\title{
Changes in renal papillary density after hydration therapy in calcium stone formers
}

\author{
Pietro Manuel Ferraro ${ }^{1,5^{*}}$ (D), Matteo Vittori ${ }^{2,5 \dagger}$, Giuseppe Macis ${ }^{3,5}$, Alessandro D’Addessi ${ }^{2,5}$, Gianmarco Lombardi ${ }^{1,5}$, \\ Claudia Palmisano ${ }^{3,5}$, Jacopo Gervasoni ${ }^{4,5}$, Aniello Primiano ${ }^{4,5}$, Pier Francesco Bassi ${ }^{2,5}$ and Giovanni Gambaro ${ }^{1,5}$
}

\begin{abstract}
Background: Previous studies have shown that, compared with non-stone formers, stone formers have a higher papillary density measured with computer tomography (CT) scan. The effect of increased hydration on such papillary density in idiopathic calcium stone formers is not known.
\end{abstract}

Methods: Patients with recurrent calcium oxalate stones undergoing endourological procedures for renal stones at our Institution from June 2013 to June 2014 were considered eligible for enrolment. Enrolled patients underwent a baseline unenhanced $C T$ scan before the urological procedure; after endoscopic removal of their stones, the patients were instructed to drink at least $2 \mathrm{~L} /$ day of a hypotonic, oligomineral water low in sodium and minerals (fixed residue at $180^{\circ} \mathrm{C}<200 \mathrm{mg} / \mathrm{L}$ ) for at least 12 months. Finally, the patients underwent a follow-up unenhanced CT scan during hydration regimen.

Results: Twenty-five patients were prospectively enrolled and underwent baseline and follow-up CT scans. At baseline, mean papillary density was $43.2 \pm 6.6$ Hounsfield Units $(\mathrm{HU})(43.2 \pm 6.7$ for the left kidney and $42.8 \pm 7.1 \mathrm{HU}$ for the right kidney). At follow-up and after at least 12 months of hydration regimen, mean papillary density was significantly reduced at $35.4 \pm 4.2 \mathrm{HU}(35.8 \pm 5.0$ for the left kidney and $35.1 \pm 4.2 \mathrm{HU}$ for the right kidney); the mean difference between baseline and follow-up was $-7.8 \mathrm{HU}$ (95\% confidence interval - 10.6 to $-5.1 \mathrm{HU}, p<0.001$ ).

Conclusions: Increased fluid intake in patients with recurrent calcium oxalate stones was associated with a significant reduction in renal papillary density.

Trial registration: NCT03343743, 15/11/2017 (Retrospectively registered).

Keywords: Kidney stones, CT scan, Randall's plaque, Hydration therapy

\section{Background}

Kidney stones are an increasingly common condition, with an estimated prevalence in the United States of about 10\%; [1] similar figures have been reported in European populations. [2] This condition is characterized by a relatively high frequency of recurrence [3] and elevated direct and indirect costs. [4] Kidney stones are most commonly composed of calcium; [5] a frequently seen lesion in calcium stone formers is the presence of suburothelial deposits of calcium phosphate known as Randall's plaques, which are thought to be the precursor

\footnotetext{
* Correspondence: pietromanuel.ferraro@unicatt.it

†Pietro Manuel Ferraro and Matteo Vittori contributed equally to this work.

${ }^{1}$ U.O.C. Nefrologia, Fondazione Policlinico Universitario A. Gemelli IRCCS,

Roma, Italia

${ }^{5}$ Università Cattolica del Sacro Cuore, Roma, Italia

Full list of author information is available at the end of the article
}

lesion of idiopathic calcium oxalate stones. [6] Previous studies have shown that, compared with non-stone formers, stone formers have a higher papillary density measured with computer tomography (CT) scan, [7-11] likely reflecting the amount of calcium deposition within the renal parenchyma; it has also been suggested that papillary density values might correlate with first incident stones [12] and recurrent stones [13]. To date however, the effect of increased hydration on such papillary density in idiopathic calcium stone formers is not known. In our study, we analyzed changes in papillary density in recurrent idiopathic calcium stone formers before and after recommendations to increase fluid intake following urological stone removal.

(c) The Author(s). 2018 Open Access This article is distributed under the terms of the Creative Commons Attribution 4.0 International License (http://creativecommons.org/licenses/by/4.0/), which permits unrestricted use, distribution, and reproduction in any medium, provided you give appropriate credit to the original author(s) and the source, provide a link to the Creative Commons license, and indicate if changes were made. The Creative Commons Public Domain Dedication waiver (http://creativecommons.org/publicdomain/zero/1.0/) applies to the data made available in this article, unless otherwise stated. 


\section{Methods}

Patients undergoing endourological procedures for renal stones at our institution from June 2013 to June 2014 were considered eligible for enrolment. Inclusion criteria were recurrent stone disease and calcium oxalate stones ( $>50 \%$ of the stone made of calcium oxalate). Stone composition was determined by Fourier transform infrared spectroscopy. Exclusion criteria were systemic conditions causing stones (hyperparathyroidism, intestinal malabsorption, renal tubular acidosis) and non-calcium oxalate stones. After signing written informed consent, patients underwent a baseline unenhanced $\mathrm{CT}$ scan before the urological procedure; the CT scans were performed using General Electric, Siemens, Philips and Toshiba equipment with a tube voltage variable from 120 to $140 \mathrm{kV}, 80-643 \mathrm{~mA}$ and slices collimation from 1 to $5 \mathrm{~mm}$. After endoscopic removal of their stones, the patients were instructed to drink at least $2 \mathrm{~L} /$ day of a hypotonic, oligomineral water low in sodium and minerals and rich in bicarbonate (fixed residue at $180{ }^{\circ} \mathrm{C}<$ $200 \mathrm{mg} / \mathrm{L}$ ) for at least 12 months (Table 1). During follow-up, patients were contacted by phone every 34 months in order to maintain their adherence to increased hydration; at the first follow-up phone contact, patients were also asked to quantify the amount of fluid increase in terms of glasses per day (a glass would correspond to about $200 \mathrm{~mL}$ of water). Finally, the patients underwent a follow-up unenhanced CT scan during hydration regimen; this second $\mathrm{CT}$ was performed using similar technical specifications to the baseline CT scan. At that time point, blood and 24-h urine samples were also collected. Renal papillary density values were evaluated on baseline and follow-up CT scans and recorded as Hounsfield Unit (HU) values.

Six papillae were measured in each renal unit by randomly choosing two papillae from each of the major renal calyces (upper, middle and lower), as such that the densities of 12 renal papillae per patient were measured, and their means calculated. The images were magnified to $5 \times$ to prevent contamination of the region of interest with the fat in the renal sinus. The measurements of the renal papillae were made taking an area of $10 \mathrm{~mm}^{2}$.

Table 1 Composition of the study water

\begin{tabular}{ll}
\hline Sodium & 4.7 \\
Calcium & 57 \\
Magnesium & 3.5 \\
Potassium & 0.5 \\
Bicarbonate & 178 \\
Fixed residue at $180^{\circ} \mathrm{C}$ & 178 \\
$\mathrm{pH}$ & 7.47 \\
\hline All values expressed as $\mathrm{mg} / \mathrm{L}$ except for $\mathrm{pH}$ &
\end{tabular}

All urine and serum analytes were measured in the central laboratory of Fondazione Policlinico Universitario Gemelli IRCCS on a Siemens ADVIA chemistry XPT with the following exceptions: urine citrate and oxalate were measured with LTA kit for enzymatic colorimetric determination.

\section{Statistical analysis}

Continuous variables were reported as means and standard deviations; categorical variables as frequencies and percentages. Arithmetic means of right and left renal papillary density measurements for each patient were calculated and used for statistical analysis. Differences between baseline and follow-up papillary density values were analyzed with paired t-tests; correlations between continuous variables were analyzed with Spearman tests. A $p$-value $<0.05$ was considered statistically significant. Statistical analyses were performed with Stata 13.1 (StataCorp, TX, USA).

\section{Results}

Twenty-five patients were prospectively enrolled and underwent baseline and follow-up CT scans. Mean age at enrollment was $57 \pm 17$ years (range 18 to 78 years), $20(80 \%)$ were males; average follow-up time was $22 \pm 5$ months (range 13 to 32 months); 22 patients received ureteroscopy and 3 percutaneous nephrolithotomy. All patients underwent measurements of papillary density on both kidneys except for one patient who had measurements taken only on the right kidney. At baseline, mean papillary density was $43.2 \pm 6.6 \mathrm{HU}(43.2 \pm 6.7$ for the left kidney and 42.8 $\pm 7.1 \mathrm{HU}$ for the right kidney). At follow-up and after at least 12 months of hydration regimen, mean papillary density was significantly reduced at $35.4 \pm 4.2 \mathrm{HU}$ $(35.8 \pm 5.0$ for the left kidney and $35.1 \pm 4.2 \mathrm{HU}$ for the right kidney); the mean difference between baseline and follow-up was $-7.8 \mathrm{HU}$ (95\% confidence interval - 10.6 to $-5.1 \mathrm{HU}, p<0.001)$. Individual changes in papillary density are represented in Fig. 1. The median self-reported increase in fluid intake during follow-up was 3 glasses (range 0 to 5 glasses). Blood and 24-h urine measurements performed at the time of follow-up CT scan are reported in Table 2. There was no correlation between the absolute change in papillary density and any of the laboratory measurements.

\section{Discussion}

In our study, we found that a course of hydration with oligomineral water after urological procedures of stone removal was associated with a significant reduction in renal papillary density as assessed with CT scan in a group of patients with recurrent calcium oxalate stones. 

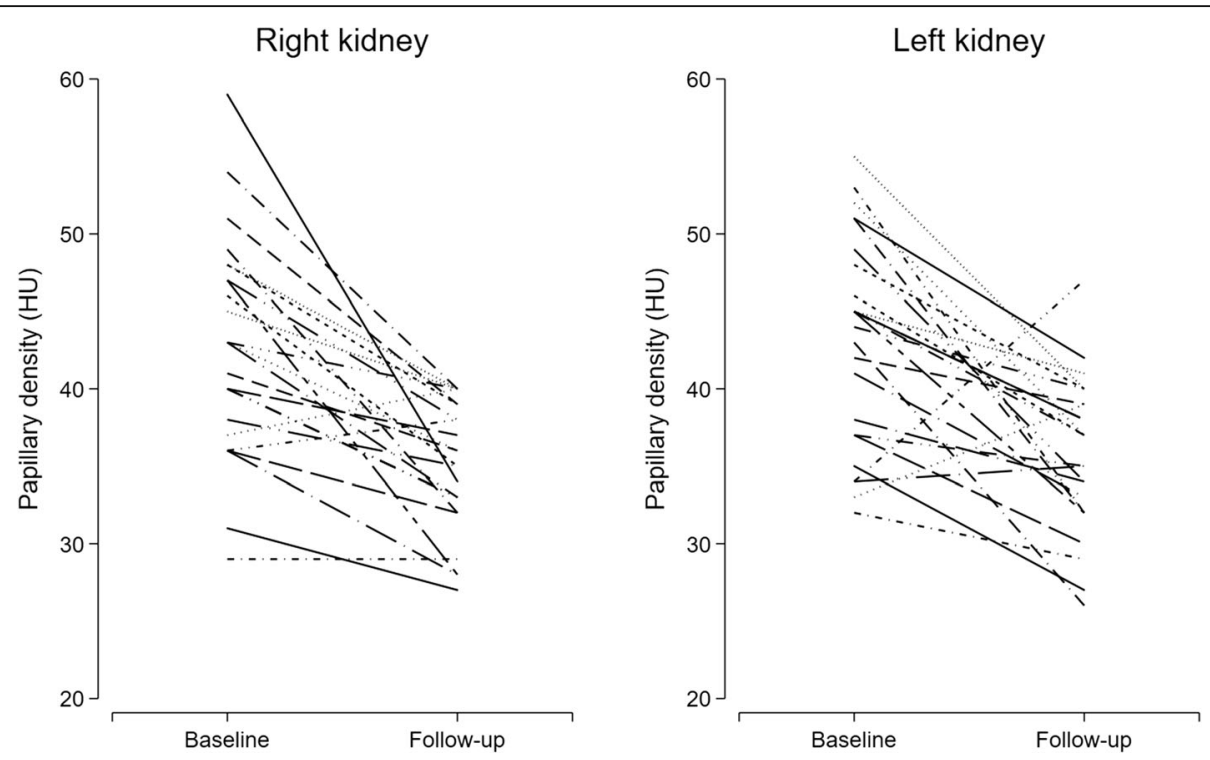

Fig. 1 Individual changes in renal papillary density before and after hydration

Several studies have investigated the association between kidney stones and increased renal papillary density. [7-11] Most studies found that the higher papillary density in stone formers is similar in affected and unaffected kidneys; it also seems to be independent of stone composition. [14] A few, retrospective, studies have also linked higher papillary density to higher likelihood of developing a first stone [12], as well as recurrent stones [13]. Only one study looked at the relationship between papillary

Table 2 Blood and 24 h urine chemistries

\begin{tabular}{ll}
\hline Blood & \\
Creatinine $(\mathrm{mg} / \mathrm{dL})$ & $0.98(0.23)$ \\
Calcium $(\mathrm{mg} / \mathrm{dL})$ & $9.9(0.3)$ \\
Phosphate $(\mathrm{mg} / \mathrm{dL})$ & $3.4(0.8)$ \\
Magnesium $(\mathrm{mg} / \mathrm{dL})$ & $2.1(0.1)$ \\
Sodium $(\mathrm{mEq} / \mathrm{L})$ & $141(2)$ \\
Potassium $(\mathrm{mEq} / \mathrm{L})$ & $4.6(0.7)$ \\
24 h urine & \\
Volume $(\mathrm{mL} / 24 \mathrm{~h})$ & $2005(765)$ \\
Creatinine $(\mathrm{mg} / 24 \mathrm{~h})$ & $786(340)$ \\
Calcium $(\mathrm{mg} / 24 \mathrm{~h})$ & $98(58)$ \\
Citrate $(\mathrm{mg} / 24 \mathrm{~h})$ & $459(208)$ \\
Oxalate $(\mathrm{mg} / 24 \mathrm{~h})$ & $19(13)$ \\
Uric acid $(\mathrm{mg} / 24 \mathrm{~h})$ & $425(192)$ \\
Phosphate $(\mathrm{mg} / 24 \mathrm{~h})$ & $439(164)$ \\
Magnesium $(\mathrm{mg} / 24 \mathrm{~h})$ & $56(27)$ \\
Sodium $(\mathrm{mEq} / 24 \mathrm{~h})$ & $83(30)$ \\
Potassium $(\mathrm{mEq} / 24 \mathrm{~h})$ & $31(12)$ \\
\hline Da &
\end{tabular}

Data are expressed as means (standard deviation) density and the urinary metabolic profile, particularly urinary calcium excretion, and found no association, [11] which is consistent with our findings of a lack of association between changes in papillary density and blood and urine chemistries. Average HU values in previous studies ranged from 37 to 54 for stone formers and from 21 to 37 for controls, with some degree of heterogeneity likely explained by different study populations. Baseline HU values in our study $(43.2 \mathrm{HU})$ were similar to those reported for stone formers in previous studies (average 42.1 HU, range 35.6 to $54.4 \mathrm{HU})$; [7-11] interestingly, follow-up HU values in our study $(35.4 \mathrm{HU})$ were closer to the range of $\mathrm{HU}$ values previously reported for non-stone formers in those studies (average 29.5 HU, range 21.0 to $36.6 \mathrm{HU}$ ).

An adequate intake of fluids is regarded as one of the mainstays of treatment for stone disease; $[15,16]$ a randomized controlled trial on patients at their first episode of idiopathic calcium stone showed that increasing water intake to obtain $2 \mathrm{~L}$ of urine per day or more reduced the risk of recurrence at 5 years by about 55\%. [17] Despite the proven efficacy of hydration in stone disease, changes in renal papillary density associated with increased water intake have not been investigated before. The results of our study suggest that increased fluid intake is likely to modify the concentration of lithogenic salts in the renal tissue; whether these changes would reflect in an actual reduction in risk of recurrence remains to be elucidated. Our study also highlights the need to include the $\mathrm{HU}$ of the renal papillae in future studies investigating interventions for stone prevention.

Our study has several strengths: a cohort composed of phenotypically homogeneous patients (recurrent calcium oxalate stone formers), whose stone composition was assessed by means of the gold-standard 
infrared spectroscopy; [18] all patients underwent the same urological procedure and the radiological images were obtained and analyzed prospectively; they all received the same indication in terms of hydration (e.g., at least $2 \mathrm{~L}$ per day of hypotonic oligomineral water) and the follow-up was relatively long (at least 12 months); furthermore, patients were asked and reminded about their increased fluid intake through phone contacts. We also had available data on blood and $24 \mathrm{~h}$ urine chemistries.

Our study also has limitations. First, we did not have a control group; however, it would not have been ethical nor feasible to not recommend increased hydration after urological removal of stones. Second, follow-up time was not identical for all participants, as it was performed on routine clinical follow-up visits based on the clinicians' judgement; however, all participants had at least 12 months of follow-up before the follow-up CT scan was performed. Third, adherence to the recommended fluid regimen was not assessed through changes in urine volume; however, the urine volume at follow-up was on average greater than $2 \mathrm{~L}$, a figure higher than expected without intervention in a group of recurrent stone formers and thus likely increased compared with baseline. Fourth, we did not have a mean to assess long-term hydration habits of the patients. Fifth, the radiologist who assessed the HU value was not blinded to the patient status; this was done in order to allow the radiologist to sample the same ROI in baseline and follow-up CT scans. Finally, the documented changes in renal papillary density could not necessarily translate into reduced risk of recurrence, despite initial evidence for a predictive role of renal papillary density in stone development; future studies are warranted to investigate whether renal papillary density and changes thereof are independent predictors of incident stone formation.

\section{Conclusions}

Increased fluid intake in patients with recurrent calcium oxalate stones is associated with a significant reduction in renal papillary density.

\section{Abbreviations}

CT: Computer tomography; HU: Hounsfield Units

\section{Acknowledgements}

Authors would like to thank the patients for their important contribution to this study.

\section{Funding}

This research did not receive any specific grant from funding agencies in the public, commercial, or not-for-profit sectors.

\section{Availability of data and materials}

Summarized data is available for publication. The authors are not able to share the data and materials used in this study, because that is not permitted by the duty of confidentiality in the strict institutional rule.

\section{Authors' contributions}

GG, PMF and AD designed the study; MV and AD performed the urological procedures; GM and CP performed the radiological studies and $\mathrm{HU}$ measurements; MV and GL performed the follow-up by phone contacts; JG and AP performed the stone composition and biochemical analyses; PMF conducted the statistical analysis; PMF, MV, GM, GL, CP and GG drafted the manuscript; $\mathrm{PB}, \mathrm{JG}$ and $\mathrm{AP}$ reviewed the manuscript for important intellectual content. All authors read and approved the final manuscript.

\section{Ethics approval and consent to participate}

This prospective study complies with the principles outlined in the declaration of Helsinki (64th World Medical Association General Assembly, Fortaleza, Brazil, October 2013) and was approved by the institutional review board of the Fondazione Policlinico A. Gemelli (protocol ID 6118/13). The aims and methodologies of this study were explained to the patients, and all subjects provided written informed consent. The study protocol was registered on clinicaltrials.gov (NCT03343743).

\section{Consent for publication}

Not applicable. This manuscript contains no individual person's data in any form.

\section{Competing interests}

The authors declare that they have no competing interests.

\section{Publisher's Note}

Springer Nature remains neutral with regard to jurisdictional claims in published maps and institutional affiliations.

\section{Author details}

${ }^{1}$ U.O.C. Nefrologia, Fondazione Policlinico Universitario A. Gemelli IRCCS, Roma, Italia. ${ }^{2}$ U.O.C. Clinica Urologica, Fondazione Policlinico Universitario A. Gemelli IRCCS, Roma, Italia. ${ }^{3}$ U.O.C. Radiologia, Fondazione Policlinico Universitario A. Gemelli IRCCS, Roma, Italia. ${ }^{4}$ U.O.C. Biochimica Clinica, Fondazione Policlinico Universitario A. Gemelli IRCCS, Roma, Italia. ${ }^{5}$ Università Cattolica del Sacro Cuore, Roma, Italia.

Received: 19 March 2018 Accepted: 26 October 2018 Published online: 12 November 2018

\section{References}

1. Scales CD, Smith AC, Hanley JM, Saigal CS. Prevalence of kidney stones in the United States. Eur Urol. 2012;62:160-5.

2. Croppi E, Ferraro PM, Taddei L, Gambaro G. Prevalence of renal stones in an Italian urban population: a general practice-based study. Urol Res. 2012:40:517-22

3. Ferraro PM, Curhan GC, D'Addessi A, Gambaro G. Risk of recurrence of idiopathic calcium kidney stones: analysis of data from the literature. J Nephrol. 2017;30:227-33

4. Saigal CS, Joyce G, Timilsina AR. Direct and indirect costs of nephrolithiasis in an employed population: opportunity for disease management? Kidney Int. 2005:68:1808-14.

5. Coe FL, Evan A, Worcester E. Kidney stone disease. J Clin Invest. 2005;115: 2598-608.

6. Matlaga BR, Coe FL, Evan AP, Lingeman JE. The role of Randall's plaques in the pathogenesis of calcium stones. J Urol. 2007;177:31-8.

7. Eisner BH, labal A, Namasivayam S, Catalano O, Kambadakone A, Dretler SP, et al. Differences in computed tomography density of the renal papillae of stone formers and non-stone-formers: a pilot study. J Endourol. 2008:22:2207-10.

8. Bhuskute NM, Yap WW, Wah TM. A retrospective evaluation of Randall's plaque theory of nephrolithiasis with CT attenuation values. Eur J Radiol. 2009;72:470-2.

9. Baran I, Voyvoda N, Tokgöz Ö, Tokgöz H. Can Hounsfield unit values of the cortex and papillae determined by computed tomography demonstrate the possibility of kidney stone formation? Eur J Radiol. 2012:81:1446-9.

10. Ciudin A, Luque Galvez MP, Salvador Izquierdo R, Diaconu MG, de Castro $A F$, Constantin V, et al. Validation of Randall's plaque theory using unenhanced abdominal computed tomography. Urology. 2013;81:246-9.

11. Shavit L, Girfoglio D, Kirkham A, Allen D, Ferraro PM, Moochhala S, et al. Increased renal papillary density in kidney stone formers detectable by CT scan is a potential marker of stone risk, but is unrelated to underlying hypercalciuria. Urolithiasis. 2016:44:471-5.

12. Ciudin A, Luque MP, Salvador R, Diaconu MG, Franco A, Collado-Belvis A, et al. The evolution of $C T$ diagnosed papillae tip microcalcifications: can we predict the development of stones? J Endourol. 2014;28:1016-21. 
13. Ciudin A, Luque MP, Salvador R, Diaconu MG, Franco A, Constantin V, et al. Abdominal computed tomography--a new tool for predicting recurrent stone disease. J Endourol. 2013;27:965-9.

14. Deshmukh S, Kambadakone A, Sahani DV, Eisner BH. Hounsfield density of renal papillae in stone formers: analysis based on stone composition. J Urol. 2015;193:1560-3.

15. Cheungpasitporn W, Rossetti S, Friend K, Erickson SB, Lieske JC. Treatment effect, adherence, and safety of high fluid intake for the prevention of incident and recurrent kidney stones: a systematic review and meta-analysis. J Nephrol. 2016;29:211-9.

16. Gambaro G, Croppi E, Coe F, Lingeman J, Moe O, Worcester E, et al. Metabolic diagnosis and medical prevention of calcium nephrolithiasis and its systemic manifestations: a consensus statement. J Nephrol. 2016;29:715-34.

17. Borghi L, Meschi T, Amato F, Briganti A, Novarini A, Giannini A. Urinary volume, water and recurrences in idiopathic calcium nephrolithiasis: a 5year randomized prospective study. J Urol. 1996;155:839-43.

18. Primiano A, Persichilli S, Gambaro G, Ferraro PM, D'Addessi A, Cocci A, et al. FT-IR analysis of urinary stones: a helpful tool for clinician comparison with the chemical spot test. Dis Markers. 2014;2014:176165.

Ready to submit your research? Choose BMC and benefit from:

- fast, convenient online submission

- thorough peer review by experienced researchers in your field

- rapid publication on acceptance

- support for research data, including large and complex data types

- gold Open Access which fosters wider collaboration and increased citations

- maximum visibility for your research: over $100 \mathrm{M}$ website views per year

At BMC, research is always in progress.

Learn more biomedcentral.com/submissions 